\title{
Dual resonance element for broadband reflectarray antenna
}

\author{
M. Hashim Dahri', M. R. Kamarudin², M. H. Jamaluddin³, M. Inam ${ }^{4}$, \\ S. Z. N. Zool Ambia ${ }^{5}$, N. Shafie ${ }^{6}$ \\ 1,3,4,5,6 Wireless Communication Centre (WCC), School of Electrical Engineering, Universiti Teknologi Malaysia (UTM), \\ 81310 Skudai, Johor, Malaysia \\ ${ }^{2}$ Centre for Electronic Warfare, Information and Cyber, Cranfield Defence and Security, Cranfield University, \\ Defence Academy of the United Kingdom, Shrivenham, SN6 8LA, UK
}

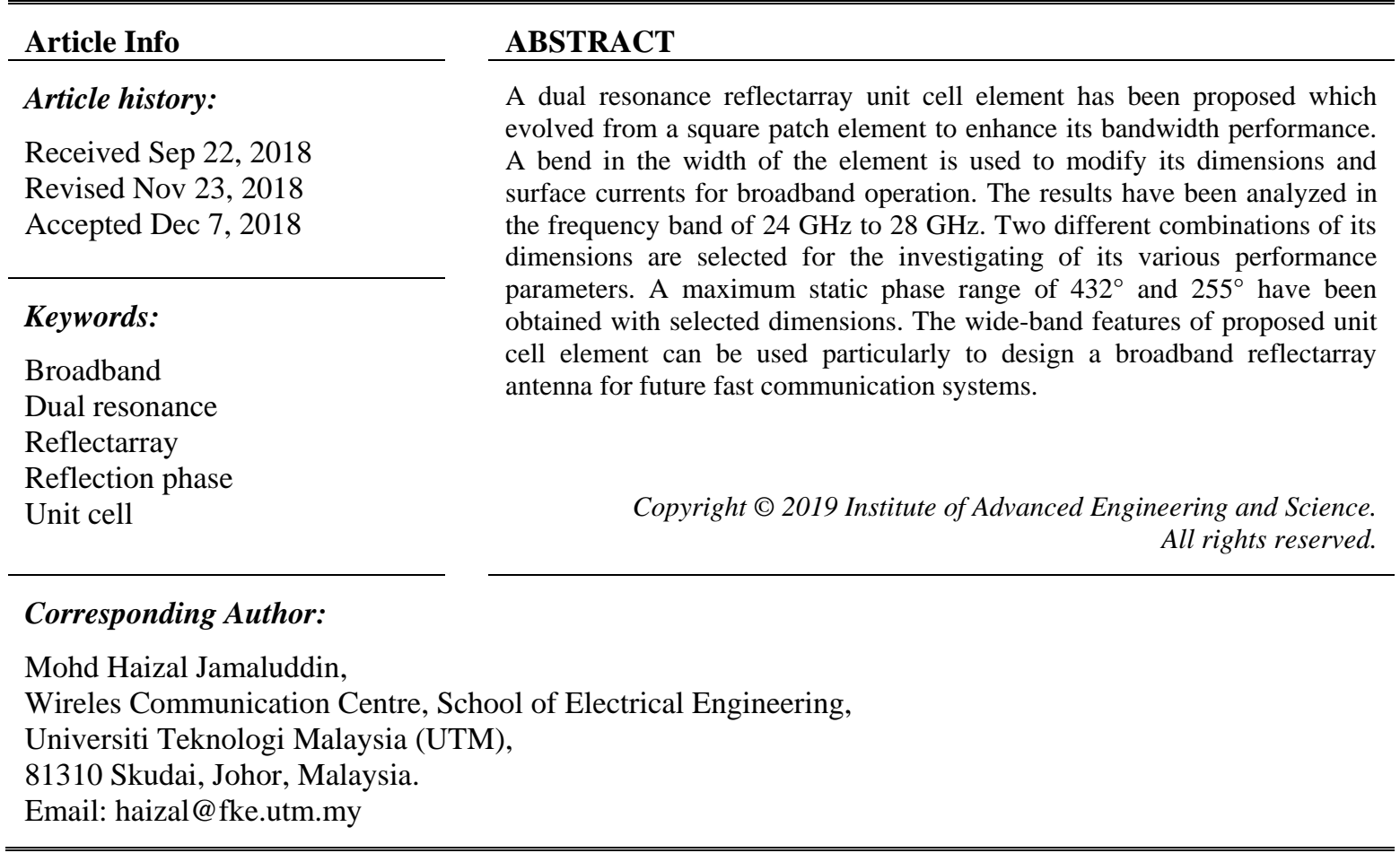

\section{INTRODUCTION}

A microstrip reflectarray antenna consists of an array of patches printed on a flat grounded dielectric substrate [1]. It replaces the parabolic reflectors and phased arrays by its low profile design and beam scanning capabilities [2]. The design and arrangement of the patches on the reflectarray surface refer to provide desired results. A reflectarray layout has been shown in Figure 1 with an offset feed operation to reflect the incident signals with a planar wave-front. The planar wave-front is required for a high gain operation with low side lobe level [3]. Moreover, it also defines a wide operational range of frequency for selected reflectarray. An appropriate design of its unit cell element is solely responsible for its high performance operation [4]. However, reflectarray possesses drawbacks of limited bandwidth and low gain performance [5]. This issue is even more challenging at high frequencies such as millimeter waves due to shorter operational wavelengths [6]. The bandwidth of a reflectarray can be enhanced by a wide-band unit cell element with wide reflection phase range [7]. Its gain depends on the reflection losses conceded by its unit cell element. Most of the conventional and low loss unit cell reflectarray elements such as rectangular and square elements have limited reflection phase range with large phase errors [8]. Phase error is a phenomenon which restricts an element to acquire a full reflection phase swing of $360^{\circ}$, which is essential for a planar wave-front. This can be eliminated by selecting broadband elements such as rings and dipoles or a multi-resonance element. A multi-resonance element has the ability to extend its reflection phase swing beyond a single resonant frequency. However, elements with wide reflection phase range are usually restricted by high reflection loss performance. 


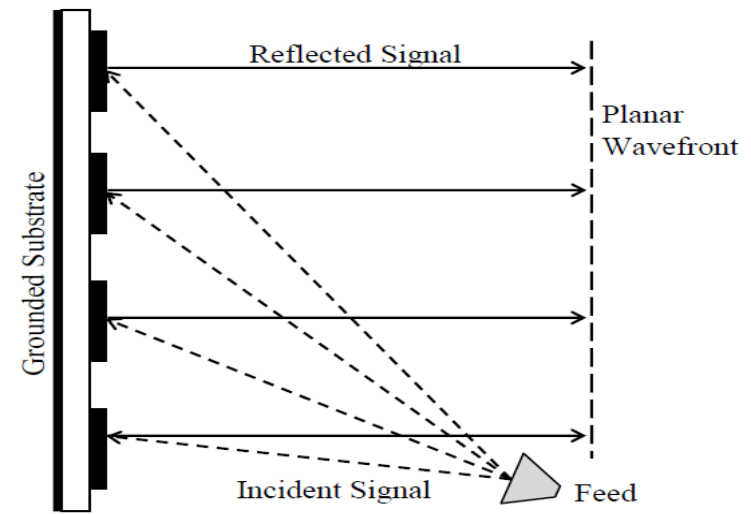

Figure 1. Reflectarray antenna design layout

Therefore in this work, a dual resonance reflectarray element has been designed with wide reflection phase range and optimized reflection loss performance. The element has evolved from a square patch operating in a frequency range of $24 \mathrm{GHz}$ to $28 \mathrm{GHz}$ proposed for future fast communication systems [9]. A detailed parametric study of the unit cell element is presented in [10]. However in this paper, two different combinations of lengths and widths of the element have been selected to analyze its reflection characteristics by Finite Integral Method (FIM). The concentration of electric currents on the surface of selected element has also been examined in relation with its resonance performance.

\section{DESIGN CONSIDERATIONS}

A square patch element offers a single frequency operation, in order to extend its operation for an extra resonance requires a change in its design configuration. Figure 2 depicts the design of the selected wide-band reflectarray element. It can be seen from Figure 2 that, a bend in the width of the square patch has been introduced at the upper right corner. This embedded bend is used to modify the surface currents of square patch element in extent to achieve an extra resonance for reflection phase modification. Table 1 summarizes the selected dimensions of the unit cell element with its resonant frequencies where " $d$ " represents the bend depth (W2-W1). The first combination of dimension provides two resonances at 25.7 $\mathrm{GHz}$ and $26.5 \mathrm{GHz}$, whereas other combination is used to combine both resonances at a single frequency of $26 \mathrm{GHz}$.

Table 1. Selected Dimensions of Broadband Unit Cell Element

\begin{tabular}{|c|c|c|}
\hline Parameter & Combination 1 & Combination 2 \\
\hline $\mathrm{d}(\mathrm{mm})$ & 0.41 & 0.24 \\
\hline L1 (mm) & 3.59 & 3.58 \\
\hline $\mathrm{L} 2(\mathrm{~mm})$ & 3.61 & 3.59 \\
\hline $\mathrm{W} 1(\mathrm{~mm})$ & 3.36 & 3.46 \\
\hline $\mathrm{W} 2(\mathrm{~mm})$ & 3.77 & 3.7 \\
\hline Resonant Frequency $(\mathrm{GHz})$ & 25.7 & 26 \\
\hline
\end{tabular}

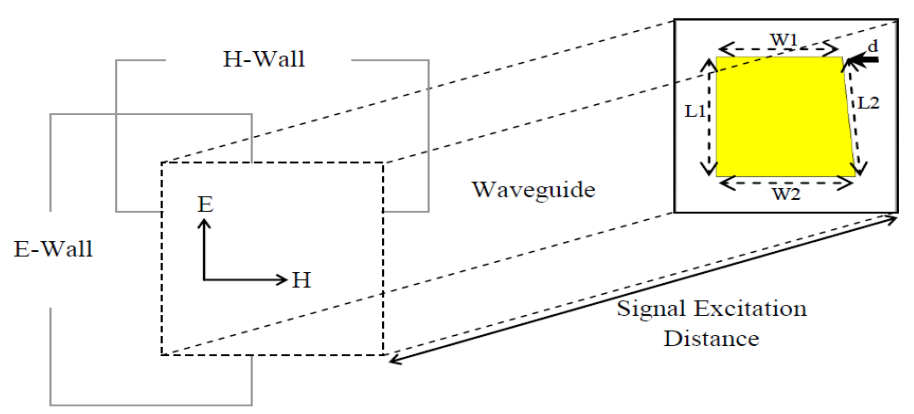

Figure 2. Infinite array approach for reflectarray unit cell element 
The modified unit cell element is then used as an infinite reflectarray element with proper boundary conditions for performance optimization. The $\mathrm{H}$-wall waveguide simulator tactic as shown in Figure 2 is used to examine the series of results. The incident signal has been excited from a distance of a quarter guided wavelength to acquire maximum reflections. Rogers 5880 dielectric material with a thickness of $0.256 \mathrm{~mm}$ is selected as substrate due to its less dielectric losses. The selected substrate thickness provides a clear observation of reflectarray unit cell performance at the prescribed frequency range.

\section{FORMATION OF TWO RESONANCES}

The resonant behavior of a microstrip patch depends on its electrical dimensions and the flow of current on its surface. As aforementioned, the bend in the width of the square element has been embedded to form a broadband element. The width incorporated bend provides two different combinations of lengths and widths, where each combination is related with a single resonant frequency for the unit cell element. Similarly the change in the dimensions also modifies the surface currents $(\mathrm{J})$ and changes their direction of flow. Figure 3 depicts the surface current flow for two selected combination of dimensions of dual resonance element. It can be observed from Figure 3(a) that, due to a bend in the width the surface current flows diagonally instead of a conventional vertical flow. Because of this reason it breaks into horizontal and vertical components called $\mathrm{J}_{\mathrm{x}}$ and $\mathrm{J}_{\mathrm{y}}$ respectively. Additionally, surface currents are also related with incident electric field (E) by the relation shown in (1) [11].

$$
E=\frac{J}{\sigma}=\frac{J_{x}+J_{y}}{\sigma}=\frac{J \cos \theta+J \sin \theta}{\sigma}
$$

Where: $\sigma$ is conductivity of patch, and $\theta$ is angle of the flow of surface currents
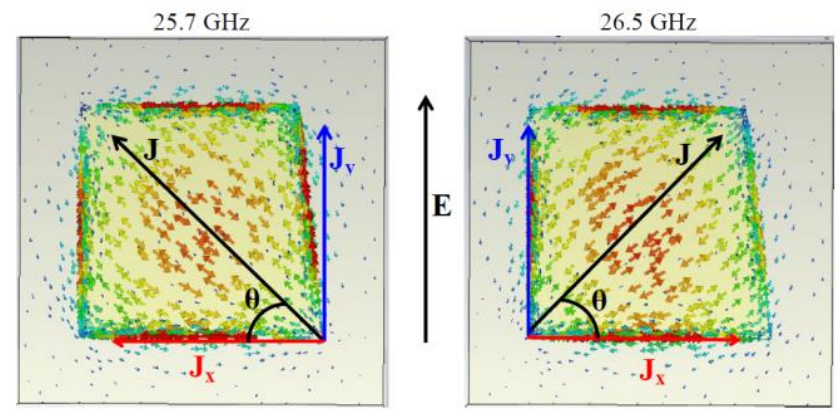

(a) Combination 1

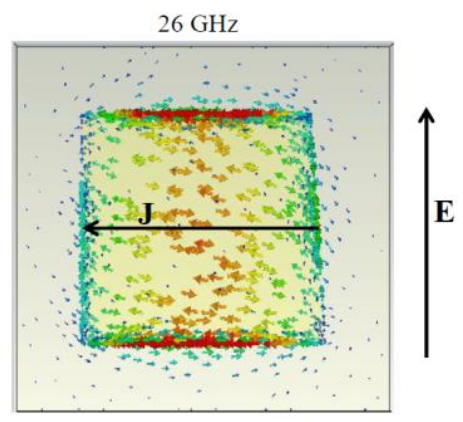

(b) Combination 2

Figure 3. Flow of surface currents at resonant frequencies of dual resonance element

As shown is (1) shows that, the change in surface currents also modifies the electric field. Moreover, two components of surface currents are responsible to produce two different values for electric field which are related with two different resonances. A value of zero for $\theta$ represents $\mathrm{J}$ with a dominant JX component, as shown in Figure 3(b). This single component of surface current combines two resonances closely together at a single frequency. The results related to each combination of dimensions of the broadband element have been discussed in the next section.

\section{RESULTS AND DISCUSSIONS}

The selected broadband reflectarray resonant element has been analyzed using infinite array approach. Two different combinations of dimensions are tested for various reflection parameters. Reflection loss and reflection phase curves of selected combinations of dimensions has been depicted in Figure 4. The element bandwidth has been calculated moving $20 \%$ above the maximum loss value whereas the static phase range defines the linearity in the slop of reflection phase curve. It has been observed from Figure 4 that, selected element with both combination of dimensions attains a reflection phase range of more than $600^{\circ}$. This confirms the dual resonance response of the broadband element. Figure 4(a) depicts that, the two resonant frequencies extend the linearity in the reflection phase range. 


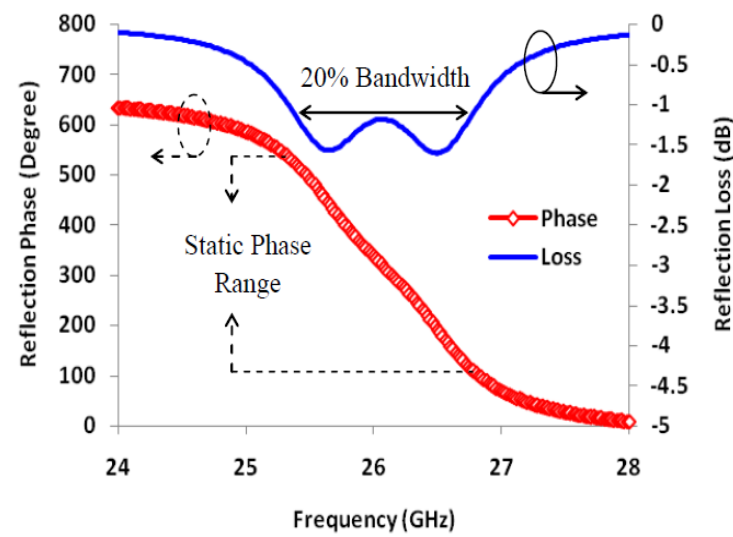

(a) Combination 1

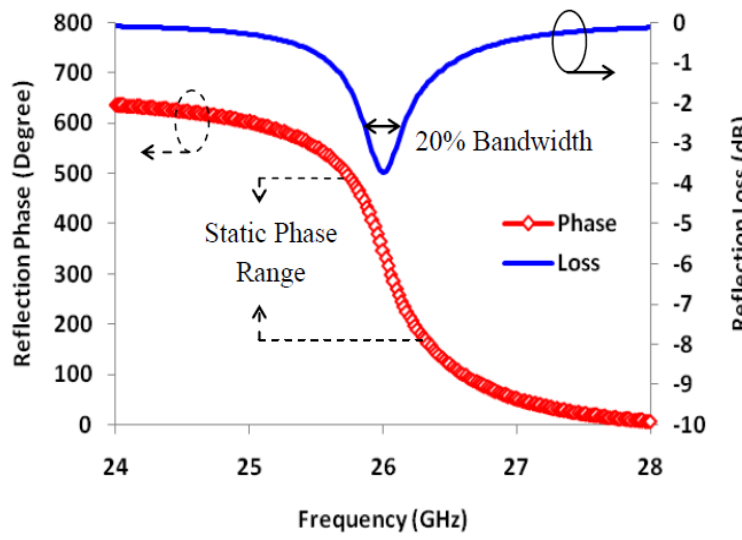

(b) Combination 2

Figure 4. Reflection loss and reflection phase curves of broadband element with selected combinations of dimensions

On the other hand, Figure 4(b) shows a comparatively narrower static phase range due to the super imposed resonances at a single frequency. Table 2 summarizes the performance parameters of broadband reflectarray element. It can be seen from Table 2 that, the first combination of dimensions acquires less reflection loss performance as compared to the second combination. The reason behind that is the higher surface current concentration of combination 2 which is $1961 \mathrm{~A} / \mathrm{m}$, as compared to combination 2 . The high value of surface currents is responsible of dissipating more energy into the substrate region and escalating the loss performance. The high loss performance is also responsible of acquiring a steep reflection phase curve which reduces the element bandwidth by $0.22 \mathrm{GHz}$. On the other side, two separate resonances of first combination of dimensions provide comparatively wider bandwidth of $0.501 \mathrm{GHz}$ and $0.487 \mathrm{GHz}$. Additionally, two resonances also smooth the slop of reflection phase curve and increase the static phase range up to $432^{\circ}$. Alternatively, the narrow bandwidth of second combination of dimensions also attains a narrow static phase range of $255^{\circ}$.

Table 2. Performance Analysis of Broadband Dual Resonance Element

\begin{tabular}{cccc}
\hline Parameter & \multicolumn{2}{c}{ Combination 1 } & Combination 2 \\
\hline Resonant Frequency $(\mathrm{GHz})$ & 25.7 & 26.5 & 26 \\
Reflection Loss $(\mathrm{dB})$ & 1.58 & 1.62 & 3.7 \\
Surface Current $(\mathrm{A} / \mathrm{m})$ & 1126 & 1240 & 1961 \\
20\% Bandwidth $(\mathrm{GHz})$ & 0.501 & 0.487 & 0.220 \\
Static Phase Range $\left({ }^{\circ}\right)$ & \multicolumn{2}{c}{432} & 255 \\
\hline
\end{tabular}

\section{CONCLUSION AND FUTURE CHALLENGES}

Two different combinations of lengths and widths have been taken into account for a unit cell reflectarray element with bend in its width to analyze it reflection performance. It has been concluded that, a conventional square patch element can be extended to operate at two different resonances in order to enhance its bandwidth performance. The formation of two resonances is linked with the change in the dimensions and the surface current distributions of the element. The simple design of patch element can make it more feasible for the future fabrication and measurements. The broadband element discussed in this work can be used to eliminate the phase errors from a full reflectarray antenna for its broadband operation.

The change in the direction of surface currents of unit cell element can affect the reflected electric field orientation. The $\mathrm{x}$ and $\mathrm{y}$ components of surface currents are related to their respective reflection polarization. This effect can alter the polarization performance of reflectarray antenna. Moreover, the leakage currents can also be generated on the element due to a change in the current distributions for dual resonance. The leakage currents can affect a full reflectarray performance by producing high cross-polarization level with limited efficiency. These two major issues can be controlled by designing a reflectarray antenna with an optimized arrangement of elements on its surface. A thorough investigation on the design of reflectarray is required in this regard, which is under consideration as a potential future aspect. 


\section{ACKNOWLEDGEMENTS}

This project is sponsored by the Ministry of Education Malaysia, Ministry of Science Technology and Innovation (MOSTI) and Universiti Teknologi Malaysia under Vot 4J211, Vot 03G33 and Vot 4S134.

\section{REFERENCES}

[1] J. Huang and J. Encinar, "Reflectarray antennas," New Jersey, USA: Wiley Inter Science, 2007.

[2] M. Kaynak, et al., "Wide-angle scanning active transmit/receive reflectarray," IET Microwaves, Antennas \& Propagation, 2014, pp. 811-818.

[3] S. V. Polenga, et al., "Millimeter-wave waveguide reflectarray," 2015 International Siberian Conference on Control and Communications, SIBCON 2015 - Proceedings, 2015.

[4] M. Bozzi, S. Germani, and L. Perregrini, "A figure of merit for losses in printed reflectarray elements," IEEE Antennas and Wireless Propagation Letters, 2004, pp. 257-260.

[5] J. Huang, "Analysis of microstrip reflectarray antenna for microspacecraft applications," report, 1995.

[6] M. Hashim Dahri, et al., "Performance Investigation of Reflectarray Resonant Elements for 5G Communications," IEEE Asia-Pacific Conference on Applied Electromagnetics (APACE-2016), Dec 2016.

[7] M. Inam and M. Y. Ismail, "Reflection loss and bandwidth performance of X-band infinite reflectarrays: simulations and measurements," Microwave and Optical Technology Letters (MOTL), vol. 53, pp. 77 — 80, 2011.

[8] David M. Pozar, et al., "Design of millimeter wave microstrip reflectarrays," IEEE Transactions on Antennas and Propagation, vol. 45, issue. 2, pp. 287-296, 1997.

[9] ITU, "Final Acts WRC-15," World Radiocommunication Conference, report, Dec 2015.

[10] M. Hashim Dahri, et al., "Broadband Resonant Elements for 5G Reflectarray Antenna Design" TELKOMNIKA (Telecommunication Computing Electronics and Control), vol. 15, no. 1, 2017.

[11] David. M Pozar, "Microwave Engineering," John Wiley and sons, 2005.

\section{BIOGRAPHIES OF AUTHORS}

\begin{tabular}{|c|c|}
\hline & $\begin{array}{l}\text { Muhammad Hashim Dahri received the B.E degree in Telecommunications from the Mehran } \\
\text { University of Engineering and Technology (MUET), Pakistan, in } 2010 \text { and the Masters by } \\
\text { Research degree in Electrical Engineering from Universiti Tun Hussein Onn Malaysia (UTHM) } \\
\text { in 2014. He is currently pursuing the Ph.D degree with the Wireless Communication Centre } \\
\text { (WCC), Univerisiti Teknologi Malaysia (UTM). He has authored over } 20 \text { research papers in } \\
\text { various indexed journals and conference proceedings. His research interests include reflectarray } \\
\text { antennas, planar printed antennas and tunable materials for antenna design. }\end{array}$ \\
\hline & $\begin{array}{l}\text { Muhammad Ramlee Kamarudin obtained his first degree from Universiti Teknologi Malaysia } \\
\text { (UTM), Johor Bahru, Malaysia, with honors, majoring in electrical and telecommunication } \\
\text { engineering and graduating in 2003. He received the M.S. degree in communication engineering } \\
\text { in } 2004 \text { from the University of Birmingham, Birmingham, UK, and later he obtained his Ph.D. } \\
\text { degree in } 2007 \text { from the same University under the supervision of Professor Peter Hall. Dr } \\
\text { Kamarudin is currently working as a Senior Lecturer at Centre for Electronic Warfare, } \\
\text { Information and Cyber (EWIC), Cranfield Defence and Security, Cranfield University, UK. He } \\
\text { is an author of a book chapter of a book entitled Antennas and Propagation for Body-Centric } \\
\text { Wireless Communications and has published more than } 200 \text { technical papers in journals and } \\
\text { proceedings including IEEE Transaction on Antenna and Propagation (TAP), IEEE Antennas } \\
\text { and Wireless Propagation Letter (AWPL), IEEE Antenna Magazine, IEEE Access, International } \\
\text { Journal of Antennas and Propagation (IJAP), Progress in Electromagnetics Research (PIER), } \\
\text { Microwave and Optical Technology Letters (MOTL), and Electronics Letters. His research } \\
\text { interests include antenna design for 5G, wireless on-body communications, in-body } \\
\text { communications (implantable antenna), RF and microwave communication systems, and antenna } \\
\text { diversity. Moreover, Dr Kamarudin is an IEEE Senior Member (SMIEEE), a Member of IET } \\
\text { (MIET), an Executive Member of Antenna and Propagation (AP/MTT/EMC), Malaysia Chapter. }\end{array}$ \\
\hline & $\begin{array}{l}\text { Mohd Haizal Jamaluddin received bachelor's and master's degrees in electrical engineering from } \\
\text { Universiti Teknologi Malaysia, Malaysia, in } 2003 \text { and 2006, respectively, and the Ph.D. degree } \\
\text { in signal processing and telecommunications from the Université de Rennes } 1 \text {, France, in } 2009 \text {, } \\
\text { with a focus on microwave communication systems and specially antennas such as dielectric } \\
\text { resonator and reflectarray and dielectric dome antennas. He is currently an Associate Professor } \\
\text { with the Wireless Communication Centre, Faculty of Electrical Engineering, Universiti }\end{array}$ \\
\hline
\end{tabular}




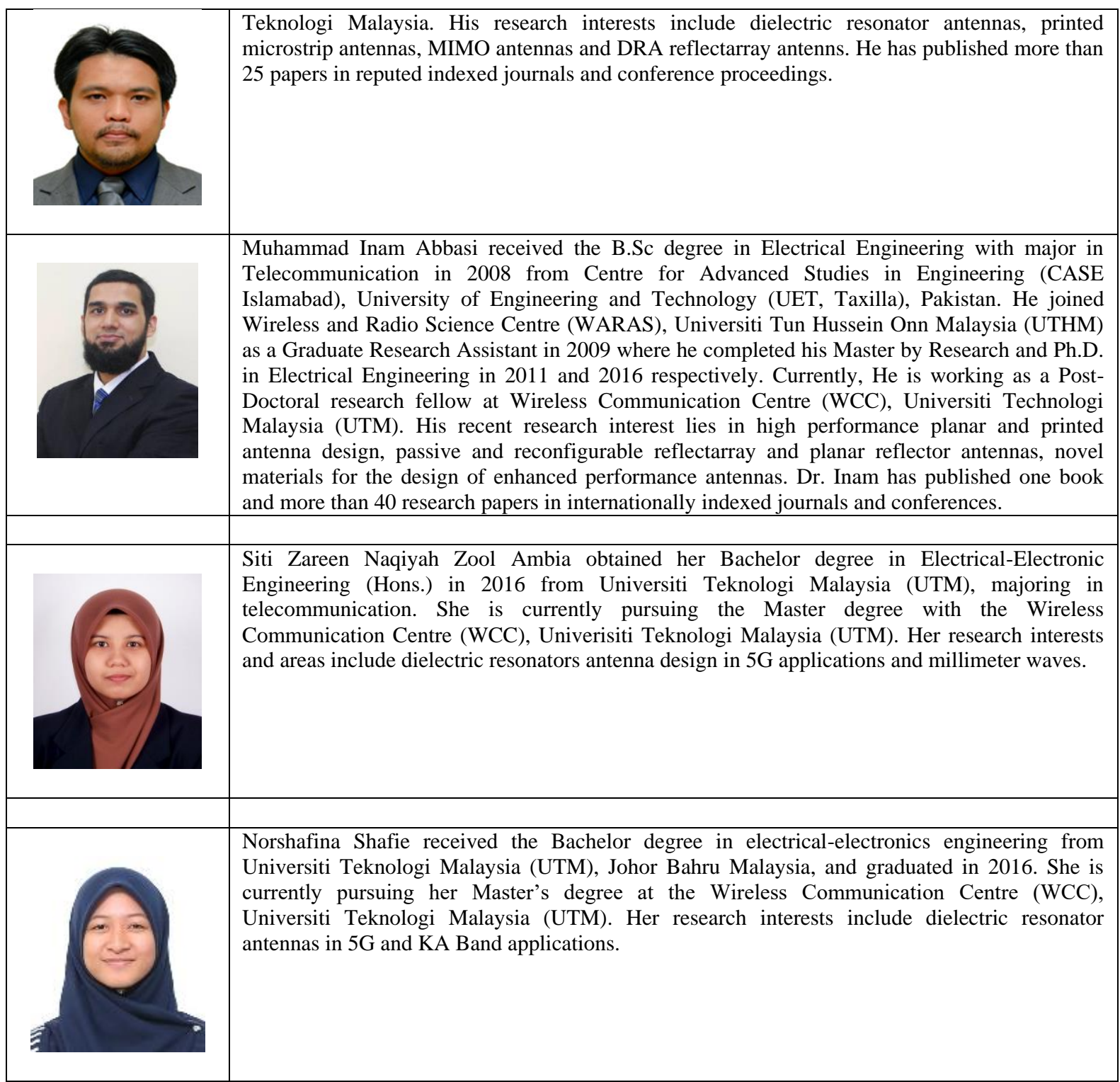

